\title{
Aproximación a la identidad étnica mapuche dentro del Movimiento Campesino Revolucionario
}

\author{
Approach to Mapuche ethnic identity within the \\ Revolutionary Peasant Movement
}

\author{
Jorge Campos Medina* \\ Camilo Farías Durán** \\ Francisca Vergara Pinto***
}

\begin{abstract}
Resumen: Este artículo devela la relación que existió entre mapuche y movimientos de izquierda en Chile desde mediados de 1960 hasta el año 1973, enfocándose en el Movimiento de Izquierda Revolucionaria (MIR), y en su frente intermedio de masas denominado Movimiento Campesino Revolucionario (MCR), el cual concentró su accionar en la Región de La Araucanía, Chile. A través de un enfoque etnográfico, utilizando como instrumentos de recolección de datos la revisión de testimonios y la realización de entrevistas en profundidad a mapuche y chilenos que participaron en el MCR, se obtuvo como resultado que las relaciones establecidas entre el grupo de izquierda y los mapuche respondían a una relación recíproca guiada por intereses de ambos grupos, como también la configuración de múltiples identidades entre quienes participaron en la acciones directas propiciadas por el MCR.
\end{abstract}

Palabras clave: Mapuche, MIR, MCR, Identidad.

\begin{abstract}
This paper reveals the historical relationship that existed between mapuche and leftist movements in Chile since middle 1960 until 1973, focusing on the Movimiento de Izquierda Revolucionaria (MIR), and on its intermediate front of mass denominated Movimiento Campesino Revolucionario (MCR), whose action was concentrated in the Región de La Araucania, Chile. An ethnographic approach with testimonies and in-depth interviews with mapuche and chileans who participated in the MCR were used as instruments of data collection. The relationships established between the left group and the mapuche responded to a reciprocal relationship guided by interests of both groups, as well as the configuration of multiple identities between those who participated in the direct actions promoted by the MCR.
\end{abstract}

Keywords: Mapuche, MIR, MCR, Identity.

\footnotetext{
* Chileno, autor. Antropólogo sociocultural, Universidad Austral de Chile jorge.camposmedina@gmail.com

** Chileno, autor. Antropólogo sociocultural. Correo: camilo.fariasduran@gmail.com

*** Chilena, coautora. Antropóloga sociocultural. Correo: franverggara@gmail.com
} 


\section{Introducción}

El presente artículo tiene como objetivo aproximarse a lo concerniente a las identidades, cómo estas cambian, se mantienen o dialogan, en las personas pertenecientes a la etnia mapuche en un contexto histórico determinado. Dicho contexto se relaciona con las recuperaciones de tierras junto al Movimiento de Izquierda Revolucionaria $\left(\mathrm{MIR}^{1}\right)$, a través de su frente intermedio de masas $^{2}$ llamado Movimiento Campesino Revolucionario $\left(\mathrm{MCR}^{3}\right)$, desde mediados de 1960 hasta 1973.

Respecto al proceso de construcción de identidad mapuche en un contexto como aquel, se considera a priori la posibilidad que existía en aquella época de configurarse múltiples identidades, sin que necesariamente una excluyera a otra y haciéndose presentes de acuerdo a circunstancias determinadas, como veremos más adelante

Lo anterior se constituyó en el objetivo general de la investigación, para lo cual se tuvo que recurrir a dilucidar diversos aspectos: 1) describir y analizar la experiencia de los actores mapuche $\mathrm{y}$ chilenos que formaron parte del Movimiento Campesino Revolucionario; 2) caracterizar los lineamentos de trabajo que poseía el Movimiento Campesino Revolucionario y su relación con las demandas del pueblo Mapuche; 3) definir la función que poseía el Movimiento Campesino Revolucionario para las luchas reivindicativas del Pueblo Mapuche; y 4) identificar y analizar las nociones de identidad que poseían los integrantes mapuche del Movimiento Campesino Revolucionario en relación a éste, lo cual se encuentra descrito y analizado en mayor profundidad en Campos y Farías $(2013)^{4}$. El presente artículo tiene como propósito profundizar en el último objetivo planteado previamente.

Para comprender de mejor manera lo que sucedía entre finales de la década de 1960 y principios de 1970 es fundamental dar cuenta del contexto que existía en Chile durante ese periodo. Con base en los procesos reivindicativos y de lucha por la recuperación de la tierra que tendrían como principales actores a una gran masa de campesinos pobres y población mapuche, no podemos negar el papel activo de la Reforma Agraria en una primera instancia. Correa, Molina y Yáñez ${ }^{5}$, entienden ésta como un

\footnotetext{
${ }^{1}$ Se usará esta sigla para referirse al Movimiento de Izquierda Revolucionaria.

${ }^{2}$ Instrumento organizacional dependiente del aparato central (en este caso MIR), pero con militancia diversa y no exclusiva de la estructura central; aun así, estos frentes intermedios de masas eran los espacios perfectos para profesionalizar a los mejores cuadros, y de esta manera darles la militancia del partido.

3 Se usará esta sigla durante el presente artículo para referiste al Movimiento Campesino Revolucionario.

${ }^{4}$ La presente investigación se desprende del último objetivo de la tesis de Campos y Farías (2013) para optar al título de Antropólogo con mención en antropología sociocultural de la Universidad de Concepción, denominada "De ojos negros y sangre roja: Aproximación a la identidad étnica Mapuche dentro del Movimiento Campesino Revolucionario", el cual ha sido trabajado con mayor profundidad y agregado nuevo datos.

${ }^{5}$ CORREA, Martín. MOLINA, Raúl. YÁÑEZ, Nancy. La reforma agraria y las tierras mapuches. Chile 1962 - 1975, Santiago de Chile, Lom, 2005, 71.
} 
(...) proceso que se da en toda Latinoamérica y tiene por objeto modificar la estructura agraria hacendal, caracterizada por la concentración de tierras en manos de grandes latifundistas, y por esta vía resolver las ineficiencias productivas del sector agrario y la situación de postergación en que se encontraba el campesinado.

Es a comienzos de la década de 1960 que, desde la Casa Blanca, la administración de J. F. Kennedy presta especial atención a lo que estaba ocurriendo en toda Latinoamérica. Un nivel de exclusión social y un grotesco atraso económico-social que se encontraba en esta gran franja de naciones, solo podía producir un caldo de cultivo para las aspiraciones insurrectas y revolucionarias de sectores fuertemente influenciadas por la Revolución Cubana, como bien lo retratan Díaz y Quezada ${ }^{6}$, "el diagnóstico también establecía que si estas condiciones no eran prontamente modificadas el ejemplo cubano transformaría a la Cordillera de los Andes en la próxima Sierra Maestra".

El proyecto trazado en los Estados Unidos toma cuerpo definitivo con la firma de la Carta de Punta del Este en 1961, donde los estados latinoamericanos se comprometían a dar solución a los problemas de marginalidad y subdesarrollo, resumiéndose su ejecución en dos proyectos básicos ${ }^{7}$ :

1- Privilegiar los nacionalismos económicos latinoamericanos, concebidos alrededor de la industrialización programada, la modernización tecnológica, la unificación de los mercados y la reforma agraria con su secuela de modernización social.

2- Enfatizar la necesidad de acceder inmediata y directamente al progreso, vía las grandes empresas transnacionales que, en presencia de mercado libre y abierto puedan racionalizar la producción y potenciar la oferta, optimizar la demanda, en síntesis, modernizar la economía de los países en un plazo históricamente breve.

De esta forma se da comienzo formal en Chile a los procesos de Reforma Agraria, desde la primera ley formal del año 1962 en el gobierno de Jorge Alessandri hasta su derogación el año 1976 ya estando el país en manos de la Junta Militar e inmerso en el tortuoso curso de la cruenta Dictadura Militar.

En 1967 se dicta la Nueva Ley de Reforma Agraria $N^{\circ} 16.640$ bajo el gobierno de Eduardo Frei Montalva, que viene a ser una modificación de la "Reforma del Macetero" (propulsada por el gobierno de Jorge Alessandri Rodríguez), transformando el sistema de tenencia de tierra e incorporando en el proyecto de la Reforma Agraria a quienes trabajen la tierra; dentro de este marco entra en juego la "problemática mapuche", pero una vez más son dejados de lado como etnia originaria, y sólo entrarían bajo la categoría de campesinos pobres, no pudiendo optar a la reposición de territorios ancestrales, sino solamente a la mejora de condiciones de vida mediante inyecciones crediticias y asistencia técnica. Únicamente se expropiarían bajo este gobierno 10.682 hectáreas físicas para comunidades

${ }^{6}$ DÍAZ, Joel. QUEZADA, Edgardo. Estado, Reforma Agraria y Campesinos. El conflicto por la tierra en el Chile central desde mediados de siglo, Tesis de grado, Universidad de Concepción, $2000,41$.

${ }^{7}$ DÍAZ, op cit. 
mapuche, la minúscula cifra de siete predios en las comunas de Angol, Lumaco, Lautaro y Purén ${ }^{8}$.

El momento histórico señalado se impregnó de un fuerte dinamismo político que se vivía en el sur del país, tomando cada vez más bríos la ocupación de predios y las corridas de cercos. Es así como comienzan las ocupaciones ilegales de latifundios apoyadas por el Partido Comunista y el Partido Socialista en un primer momento, para luego entrar en activa alianza con las comunidades mapuche durante el periodo 1969-1973 adquiriendo características masivas y revolucionarias; el MCR y el Movimiento Netuaiñ Mapu (Recuperaremos la tierra), organización completamente abocada hacia la movilización mapuche dependiente del Partido Comunista Revolucionario (de tendencia maoísta).

José Bengoa ${ }^{9}$ le atribuye a este momento histórico diversas causas y/o factores que dieron el azote para el galope estrepitoso del momento:

- La nula respuesta por parte del Estado, e ineficiencia de sus mismas organizaciones para atacar directamente el tema de las devoluciones de las casi 100 mil hectáreas usurpadas.

- $\quad$ Desde la década de 1950, dentro de las comunidades se evidencian las necesidades urgentes por motivo de la alta densidad poblacional, generando crisis internas.

- La llegada y permanencia en muchas comunidades de elementos foráneos (Movimiento Campesino Revolucionario, Netuaiñ Mapu y otros partidos políticos de tendencia marxista), posibilitando de esta forma la oleada de tomas y corridas de cercos.

- La orientación de las movilizaciones sólo a la solución de determinados problemas. La dimensión "revolucionaria" fue mirada por los propietarios o por los dirigentes políticos como un síntoma del cuestionamiento generalizado a la legalidad y al orden imperante.

El 4 de noviembre de 1970 por primera vez en la historia, por medio de las urnas llegaba un político abiertamente marxista con ambiciones revolucionarias a La Moneda; Salvador Allende Gossens, militante del partido socialista y abanderado del conglomerado de partidos de izquierda (Partido Comunista, Partido Radical, Partido Socialista, Movimiento de Acción Popular Unitario (MAPU), Partido Social Demócrata, Partido de Izquierda Radical, Acción Popular Independiente, Izquierda Cristiana) llamada "Unidad Popular". Tienda política que elevó un programa de gobierno con medidas tendientes a reformar el aparato político estatal chileno y donde se imprimió una profundización del proceso de reforma agraria, a través del ministro de agricultura Jaques Chonchol ${ }^{10}$.

Por lejos el principal logro del gobierno de Allende fue la promulgación de una ley que defendiese a las comunidades indígenas del peligro de la división territorial, la que venía estando vigente desde el mandato de Alessandri (Ley $\mathrm{N}^{\circ} 14.511$ de 1960), y la aprobación de una ley que remplazase a la $\mathrm{N}^{\circ} 14.511$ era por sobre todo una promesa del

${ }^{8}$ CORREA, op. cit.

${ }^{9}$ BENGOA, José. (compilador). La Memoria Olvidada. Historia de los Pueblos Indígenas de Chile, Santiago de Chile, Cuadernos Bicentenario, 2004, 414.

${ }^{10}$ CHONCHOL, Jacques. El desarrollo de América Latina y la Reforma Agraria, Santiago de Chile, Editorial del Pacifico, 1964, 12. 
"compromiso histórico" del cerro Ñielol de $1964^{11}$. Para esto y como primer paso Allende participó en el II Congreso Nacional Mapuche celebrado en diciembre de 1970 en Temuco, evento en el cual Allende hizo su primera visita oficial como Presidente de la República, y recibió el primer borrador del proyecto de Ley, la que tiempo después sería aceptada por los sectores políticos en las cámaras legislativas, con el nombre de Ley $\mathrm{N}^{\circ} 17.729$ proponiendo esencialmente:

1. La restitución de tierras usurpadas a las comunidades. En el espacio de un año (1971) se restituyeron más de 68.000 hectáreas. La restitución de tierras usurpadas fue una sentida aspiración de las organizaciones indígenas a lo largo del siglo XX. Hasta mediados de ese siglo prácticamente un tercio de las tierras con título de propiedad habían sido usurpadas.

2. Promover un sistema cooperativo de tenencia y explotación de la tierra. Una buena disposición hacia nuevas formas de producción empezaba a manifestarse entre algunos mapuche. Por ejemplo, en la zona de la comuna de Cunco un grupo de familias iniciaba una experiencia de explotación poniendo en común tierras y maquinarias.

3. Promover el desarrollo integral del pueblo mapuche. En el plano económico, se traducía en la otorgación de asistencia técnica y de créditos agrícolas. En el plano social, en la realización de planes de vivienda, y en el aspecto educacional, construcciones escolares, internados, becas, etcétera (art. 34) ${ }^{12}$.

Se crea el Instituto de Desarrollo Indígena (IDI), para "promover el desarrollo social, educacional y cultural de los indígenas de Chile, considerando su idiosincrasia y respetando sus costumbres"; así por vez primera se definía la condición de indígena más allá de su relación con la tierra, sino también recurría a elementos culturales como su idioma, sistemas de creencia, modos de vida, etcétera. Claro que siempre desde una perspectiva integracionista, pero con el reconocimiento de los elementos configurativos propios del pueblo mapuche. Y el importantísimo ítem de la división de las comunidades, sólo se pudo asumir y analizar después de pasado por el colador del parlamento, donde dice en el artículo 14 de la ley $\mathrm{N}^{\circ}$ 17.729: "Las comunidades indígenas sólo podrán dividirse cuando lo pida al Instituto de Desarrollo Indígena la mayoría absoluta de los comuneros que vivían o trabajen personalmente en la respectiva comunidad, o cuando lo acuerde el propio Instituto"13.

Mientras en Santiago, Allende se cuelga la banda presidencial, en el sur del país, los procesos llevados a cabo por el pueblo Mapuche no se detienen. El dinamismo que el MCR y el Movimiento Netuaiñ Mapu entregó a los comuneros durante el último tercio de la década de 1960, fue de una fuerza catalizadora inmensa. Por tanto en este periodo la reivindicación de derechos se profundiza, y se expresa a través de las recuperaciones de

${ }^{11}$ FOERSTER, Rolf. MONTECINOS, Sonia. Organizaciones, líderes y contiendas mapuche (19001970), Santiago de Chile, Ediciones CEM, 1988.

${ }^{12}$ SAMANIEGO, Augusto. RUIZ, Carlos. Mentalidades y políticas wingka: Pueblo Mapuche, entre golpe y golpe (de Ibáñez a Pinochet), vol. 7, Editorial CSIC-CSIC Press, 2007.CHIHUAILAF, Arauco. Los mapuches y el gobierno de Salvador Allende (1970-1973), Sociedad y discurso, AAU, vol.5, 2004, 1-11.

${ }^{13}$ SAMANIEGO, op.cit. pp.334-335. 
tierras, y la ya patentada corrida de cercos, estrategia principal y de gran poder de contagio entre comunidades, consistente en restablecer los deslindes originales de los Títulos de Merced sobre los fundos o predios aledaños que tenían tierras mapuche usurpadas ${ }^{14}$.

La forma de movilización que se configuró en el Wallmapu (Araucanía Tradicional o Territorio ancestral) durante este periodo colocaba en el tapete las verdaderas necesidades del pueblo mapuche, y específicamente lo perentorio a la ampliación de las tierras de las comunidades, haciendo de esta forma un llamado de atención y provocación para una aceleración de la reforma agraria.

Esta estrategia política buscaba concretar y resolver de una vez por todas las demandas de la tierra de las comunidades mapuche, siempre desde un marco formal legislativo con la Ley de Reforma Agraria y la Ley Indígena $\mathrm{N}^{\circ} 14.511$. Esta plataforma de ejecución era trasladar a la ciudad de Temuco el Ministerio de Agricultura y la Corporación de Reforma Agraria (CORA), que en conjunto deberían trabajar codo a codo para agilizar los entramados legales y hacer eco de la demanda histórica del pueblo mapuche y su consiguiente expropiación de predios.

Así durante los "mil días" del gobierno de Allende, o sea específicamente entre el 4 de noviembre de 1970 y el 11 de septiembre 1973, se expropiaron en La Araucanía 574 fundos, con una superficie total de 636.288,3 hectáreas físicas, equivalentes a 7.407,77 hectáreas de riego básico ${ }^{15}$; restituyéndose como nunca jamás por parte del Estado tierras consideradas usurpadas de los títulos de merced, así como territorios ancestrales, siendo éstas casi la totalidad en las provincias de Malleco y Cautín.

De esta manera la Ley $\mathrm{N}^{\circ} 17.729$ como punta de lanza de la política indigenista del Gobierno Popular, tiene un tinte de gran significancia, ya que la implementación así como la ejecutabilidad que logró la legislación en este breve lapso de tiempo, pudo al son del ruedo del proceso, con todos los aires arrebolados que dieron el marco a este momento histórico, devolverle junto con las tierras la significancia cultural que como etnia originaria debieron haber tenido desde antaño el loable pueblo mapuche. Samaniego y Ruiz ${ }^{16}$ declaran:

Durante mil días se vivió una experiencia que avanzó hacia el reconocimiento -no solo de las "carencias", "marginalidad" indígena-, sino de la fuerza de un sujeto colectivo que interactúa con la sociedad y el Estado de Chile. Los conflictos, amplificados por las pugnas entre la izquierda allendista y la "insurreccional", marcan la otra cara de la experiencia.

\section{Antecedentes Teóricos}

Para la identificación de elementos mapuche al interior del MCR es menester enfocar nuestra mirada en los diferentes flujos teóricos que nos lleven a reconstruir esta parte de la

${ }^{14}$ CORREA, op. cit.

15 BENGOA, José. (compilador). La Memoria Olvidada. Historia de los Pueblos Indígenas de Chile, Santiago de Chile, Cuadernos Bicentenario, 2004, 414. BENGOA, op. cit., p.419.

${ }^{16}$ SAMANIEGO, op. cit., p. 354. 
historia; esto con la clara intención de confeccionar un análisis profundo para así poseer un entendimiento más acabado del tema a tratar.

En torno al concepto de cultura y cultura mapuche ${ }^{17}$, en la presente investigación consideramos lo propuesto por José Marimán ${ }^{18}$, quien concibe a la cultura en términos dialécticos, siendo algo que se encuentra en permanente cambio a través de las generaciones. Solo que, como las culturas no existen en un vacío aisladas unas de otras, los cambios obedecen tanto a imperativos internos como a los contextos en que los grupos humanos interactúan (los mapuche han interactuado con wingkas, siendo estos incas, hispano-europeos, chilenos, argentinos y otros grupos). En otras palabras, los cambios se dan por voluntad, influencia o por coerción. En el caso de los mapuche, considerando su historia, los cambios les han sobrevenido bajo las estrictas condiciones de dominación y reniego.

El concepto de identidad e identidad étnica ha sido trabajado por una gran cantidad de autores enfocados en diferentes temas y $\operatorname{contextos}^{19}$. Aquí será comprendida desde la óptica de Miguel Alberto Bartolomé20, como un construcción ideológica, histórica, contingente, relacional, no esencial, y eventualmente variable, la cual manifiesta un carácter procesual y dinámico, requiriendo referente culturales para construirse como tal y enfatizar su singularidad, como también para demarcar los límites que lo separan de otras identidades étnicas. Podemos vislumbrar que la existencia de una identidad étnica se ancla en los parámetros culturales de una sociedad, lo que es clave para marcar la diferencia con otras identidades, o sea, se puede inferir la existencia de múltiples identidades dentro de los sujetos.

17 BENGOA José, Historia de un conflicto: el Estado y los Mapuches en el Siglo XX, Santiago de Chile, Editorial Planeta Chilena S.A., 1999. BENGOA, op. cit., FOERSTER op. cit., SAAVEDRA, Alejandro, Los mapuche en la sociedad chilena actual, Santiago de Chile, Lom, 2002.

18 MARIMÁN José, Autodeterminación, Ideas políticas mapuche en el albor del siglo XXI, Santiago de Chile, Lom, 2012.

${ }^{19}$ ARAVENA Andrea, "El rol de la memoria colectiva y de la memoria individual en la conversión identitaria mapuche", Estudios Atacameños, 26, 2003, 89-96. ARAVENA, Andrea, "Etnicidad y política en América Latina: relaciones entre políticas indigenistas e identidades indígenas, Enfoques Sociológicos-Serie Contribuciones, 19, 2005, 1-53. BARI, María, "La cuestión étnica: aproximación a los conceptos de grupo étnico, identidad étnica, etnicidad y relaciones interétnicas", Cuadernos de Antropología Social, 16, 2002, 149-163. BARTH Fredick, Los grupos étnicos y sus fronteras, México, Fondo de Cultura Económica, 1976. CISTERNAS E, Proceso de construcción de la identidad mapuche en miembros de asociaciones indígenas urbanas en el Gran Concepción, Fondecyt $n^{\circ}$ 1061011, Universidad de Concepción, 2009. DÍAZ - POLANCO, Héctor (1981). "Etnia, Clase y Cuestión Nacional", Cuadernos políticos, 30, México D.F., 53-65. HERRANZ, J, y BASABE, N, "Identidad nacional, ideología política y memoria colectiva", Psicología Política, 18, 1999, 31-47. LARRAÍN, Jorge, Identidad Chilena, Santiago de Chile, Lom, 2001. MONTERO H, Identidad étnica y municipio. La nueva comuna de Chol Chol dirigida por un alcalde mapuche, Santiago de Chile, Universidad Academia de Humanismo Cristiano, 2007.

${ }^{20}$ BARTOLOMÉ, Miguel, Procesos interculturales. Antropología política del pluralismo cultural en América Latina., México, Siglo XXI Editores, 2006. 
Andrea Aravena ${ }^{21}$ hace una síntesis de lo propuesto por varios autores referente al tema, tomando en consideración que la identidad conlleva una posición personal, pero sin olvidar que dicha posición personal se ancla en un grupo social mayor, y en una caracterización para la diferenciación con un "otro", como lo vimos en el apartado anterior. Esto nos permite comprender de mejor manera la identidad mapuche, dentro de un contexto donde existe un Estado opresor, el cual a través de la historia ha hecho que la identidad mapuche salga cada vez más a la palestra, ya que como señala José Marimán ${ }^{22}$, esta última surge cuando existen tensiones y conflictos, donde se tienden a agudizar las fronteras étnicas, como bien se puede observar en el caso mapuche donde el tema de la usurpación de territorio y la tenencia de tierra se ha convertido en algo habitual, configurándose así un conflicto que lleva siglos sin ser resuelto, y que tiene como punto histórico de resalte el periodo 1970-1973, comprendiendo el clima político imperante en el país, así como la degradación que existía hacia el pueblo mapuche durante aquel momento.

El concepto de etnicidad lo comprendemos como un conglomerado de elementos culturales que configuran un grupo social determinado, generando para dicha empresa herramientas y categorías de autoadscripción a un grupo específico, haciendo propia una identidad de grupo y marcando límites diferenciables con otros. Y a la vez consideramos lo propuesto por Mariman $^{23}$, respecto a las precondiciones étnicas diferenciales, o manifestaciones propias de la cultura mapuche (degradada y remanente, que aún sobrevive y que toma la forma de lengua propia, ngillatun, palin, recuerdos, mitos, símbolos, valores, toponimia, endogamia relativa, historia, etcétera) ${ }^{24}$.

Siguiendo a Mariman ${ }^{25}$ dentro de los aspectos que configuran la etnicidad y la identidad étnica, se encuentra lo concerniente a los aspectos objetivos y subjetivos dentro de los mapuche. Uno de estos se encuentra relacionado con el conflicto, entendiendo que los conflictos que ha vivido el pueblo mapuche desde el período de la Conquista en adelante, han configurado una memoria colectiva e individual, lo que hace que el enfrentamiento, como también la usurpación hacia el pueblo Mapuche y la lucha reivindicativa, se trasformen en una categoría propia, inmiscuyéndose dentro de la etnicidad en este caso, demarcando con más fuerza la frontera argentina o chilena, según sea el caso, además de ser un referente unificador de diferentes causas comunes que dan paso a la organización y compenetración de un grupo.

Para poder vislumbrar de mejor manera lo concerniente al Movimiento Campesino Revolucionario y la relación de éste con los mapuche, se hace necesario tocar el punto sobre la identidad étnica y la identidad de clase, ya que son temas primordiales a la hora de abordar la investigación. Enfocándonos en lo que postula Alejandro Saavedra ${ }^{26}$, damos cuenta del proceso que llevó a los mapuche a convertirse en campesinos. Este proceso se configura con la obligación por parte del Estado chileno a que éstos se establecieran en

\footnotetext{
21 ARAVENA, op.cit.

${ }^{22}$ MARIMAN, op.cit.

${ }^{23}$ Ibid.

${ }^{24}$ Ibid.

${ }^{25}$ Ibid.

${ }^{26}$ SAAVEDRA, op. cit.
} 
reducciones desde mitad del siglo $\mathrm{XIX}$ hasta mediados del siglo $\mathrm{XX}^{27}$, las que luego pasaron a llamarse comunidades; donde por el terreno en que fueron obligados a estar y las condiciones de vida que se les impuso, se instauró una campesinización forzada. Esta coacción hacia el pueblo mapuche en la década de 1960 ya formaba parte de su modo de vida, ya que "hacia finales de la década de 1960 la resistencia mapuche no es solo subcultural (cultural ${ }^{28}$ ), o étnica, como dirían algunos, sino que es, al mismo tiempo, campesina y étnica" 29 .

Desde el siglo XIX el estado Chileno impuso ciertas medidas forzadas hacia la campesinización, a lo que se añade lo mencionado por Marimán ${ }^{30}$, como la calidad inadecuada de las tierras dejadas a los mapuche para la actividad agrícola, técnicas agrícolas ineficaces y carencia de experiencia en agricultura intensiva. Comprendiendo que los mapuche fueron forzados a asumir este tipo de producción, fueron obligados a forjarse como una sociedad ganadera campesina, lo que podemos notar en la siguiente cita:

Los Mapuche pudieron conservar de patrimonio 500.000 hectáreas aproximadamente, tierras reconocidas como mapuche en títulos de propiedad otorgados por el estado, entre 1884 y 1927. En promedio, informan investigadores como Bengoa y Valenzuela en 1884, los mapuche recibieron 6,1 hás., más o menos por persona, mientras que los colonos extranjeros se les asignaban 500 hás. y a los chilenos -soldados varios de ellos- parcelas de 25 hás. por vivienda y hás. extras por cada hijo. Esa situación dio origen a ambos: al mapuche campesino pobre y practicando una economía en gran medida de subsistencia, y una sociedad mapuche de pobreza ${ }^{31}$.

Es así, como escapando a los reduccionismos en torno a una identidad étnica restringida que poseerían los mapuche de las décadas de 1960 y 1970, apoyándonos en los postulados de Alejandro Saavedra ${ }^{32}$ y considerando lo trabajado por José Marimán ${ }^{33}$, esta investigación postula la existencia de identidades múltiples en los mapuche, asumiendo una identidad étnica en torno a su condición como mapuche, y una identidad de clase, comprendiendo su estilo de vida en torno a su modo de producción.

Los mapuche, con su doble identidad de indígenas y campesinos, concurren a la formación y a las acciones de un importante movimiento obrero y popular. La población mapuche se hace parte de los movimientos campesinos y los procesos de reforma agraria. A fines de la década de 1960 y durante el gobierno de la Unidad Popular los movimientos

${ }^{27}$ MARIMÁN, op. cit.

${ }^{28}$ Paréntesis puesto por los autores.

${ }^{29}$ SAAVEDRA, op. cit., p. 67.

${ }^{30}$ MARIMÁN, op. cit.

31 JARA 1995; STUCHLIK 1970; BENGOA 1985; BABAROVIC et al. 1987, citados en MARIMÁN, op. cit., p.48.

${ }^{32}$ SAAVEDRA, op. cit.

${ }^{33}$ MARIMÁN, op. cit. 
mapuche emprenden grandes movilizaciones para recuperar tierras, a través de las "corridas de cerco"34.

De esta manera no es de extrañarse que los mapuche se hayan hecho partícipes de movimientos que incentivaban la lucha por la recuperación de la tierra y la explotación de ésta, por parte de movimientos de izquierda que existían en ese periodo. Por lo mismo considerando la identidad campesina, no queremos sobreponerla a otro tipo de identidad, como lo es la étnica, sino que las entendemos como una fusión de ambas no excluyentes entre sí. Así la presente investigación, comprendiendo estas múltiples identidades, vislumbra al mapuche como campesino, asumiendo sus luchas por las mejoras de las condiciones objetivas de vida, como también comprende su condición étnica, la cual en diversas acciones se vería manifestada en su propia diferenciación con el wingka, en este caso apelando a una memoria en común, una memoria de usurpación. En esta identidad étnica también recaen los factores objetivos y subjetivos propuestos por José Marimán ${ }^{35}$ en lo correspondiente a la definición de etnia para el pueblo mapuche.

\section{Antecedentes metodológicos}

Para abordar la presente problemática de investigación, se empleó una metodología cualitativa cuyo carácter se basa en que son los objetivos los que dirigen el proceso investigativo. En palabras de Dávila ${ }^{36}$, “en la investigación cualitativa se pretende la determinación dialéctica de sentido, mediante la operación de 'desentrañar' significados (...) siempre en relación con los objetivos delimitados". Se escogió este tipo de metodología debido a que es inductiva, interactiva, reflexiva y abierta, dando cabida a lo inesperado, donde cada descubrimiento y hallazgo se puede transformar en un nuevo punto de partida de un ciclo investigativo dentro de un mismo proceso investigativo ${ }^{37}$.

En relación a esta postura metodológica y de acuerdo a la temática a estudiar, nos planteamos un estudio cualitativo desde una óptica particular. Ésta corresponde a la de tipo emic, considerando que se encuentra ligada con la perspectiva desde adentro, desde las mismas personas que nos brindaron la información para su posterior análisis. Así también se usaron dos instrumentos de recolección de datos, el primero corresponde a la entrevista, y el segundo es el análisis de fuentes documentales, las cuales nos brindaron testimonios que poseían relación directa con el objetivo de la investigación ${ }^{38}$.

Se realizaron seis entrevistas en profundidad, las cuales fueron divididas en dos categorías: tres de las entrevistas corresponden a ex-militantes chilenos del MIR que participaron en acciones del MCR, y tres entrevistas realizadas a mapuche de la comuna de

\footnotetext{
${ }^{34}$ SAAVEDRA op. cit., p.67.

${ }^{35}$ MARIMÁN, op. cit.

${ }^{36}$ DÁVILA A, "Las perspectivas metodológicas cualitativa y cuantitativa en las ciencias sociales: debate teórico e implicaciones praxeológicas, J. Delgado y J. Gutiérrez (coords.), Métodos técnicas cualitativas de investigación en ciencias sociales, Madrid, Síntesis, 1999, p. 77.

37 SANDOVAL Carlos, Investigación cualitativa, Bogotá, ARFO Editores, 2002.

38 BAEZA Manuel, De las metodologías cualitativas en investigación científico-social. Diseño y uso de instrumentos en la producción de sentido, Universidad de Concepción, 2002.
} 
Puerto Saavedra, en la Región de La Araucanía, quienes estuvieron involucrados con el MCR en las acciones directas propiciadas por este movimiento ${ }^{39}$.

Para el análisis de los datos se optó por la estrategia de análisis temático ${ }^{40}$ considerándolo más acorde al tema de investigación; con este tipo de análisis proponemos la captura de toda la variabilidad de posicionamientos posibles a propósito de un tema indagado y una serie de entrevistas ${ }^{41}$. La muestra seleccionada corresponde a seis personas, las cuales fueron diferenciadas en dos categorías para así configurar el análisis que se realiza a posterior. Una primera categoría corresponde a personas mapuche que participaron dentro del Movimiento Campesino Revolucionario, esto con el fin de captar el punto de vista de los propios actores involucrados que pertenecían a esta etnia y participaban dentro de este frente intermedio de masas. La segunda categoría corresponde a personas chilenas pertenecientes al MCR, aquí se encasillarían las personas que tuvieron una importancia política dentro del plano dirigencial, como agentes captadores e incentivadores de masas. Por lo cual su visión del cómo funcionaba esta orgánica pasa a ser de gran importancia para el análisis que se pretende realizar.

El análisis de datos textuales considera dos textos de testimonios que existen con relación al MCR, el primero corresponde al libro que agrupa testimonios llamado "A desalambrar" que tiene como editor a Rafael Railaf ${ }^{42}$ y el segundo corresponde al texto "Memorias de una lucha campesina" de autoría de Julián Bastías ${ }^{43}$. Para el análisis de los datos obtenidos en trabajo de campo, como el correspondiente a los datos secundarios, se optó por la triangulación de datos ya que es un método que otorga a una investigación y a sus distintos procedimientos una auténtica confiabilidad interna ${ }^{44}$.

\section{Los primeros pasos del Movimiento Campesino Revolucionario y aproximaciones a su forma de actuar}

La conformación oficial del MCR se efectuó en septiembre del año 1970, fecha en la cual se generan los estatutos de este frente intermedio de masas para pasar a conformar uno más de los ya existentes dentro del MIR. Pero pese a esto, aunque existe una fecha formal de la conformación del MCR, con la información recolectada podemos mencionar que los primeros esbozos que desembocaron en la fundación de este frente intermedio de masas se remonta a los últimos años de la década de 1960, fecha en que el MIR atendiendo

\footnotetext{
${ }^{39}$ Se resguardará la identidad de los entrevistados en lo concerniente a las citas extraídas de las entrevistas realizadas por los autores, categorizándose en: Entrevistado MIR 1,2,3; Entrevistado Mapuche 1,2,3.

${ }^{40}$ Ibid.

${ }^{41}$ Ibid.

${ }^{42}$ RAILAF Rafael, A desalambrar: historias de Mapuches y Chilenos en la lucha por la tierra, Editorial Ayun, 2006.

${ }^{43}$ BASTÍAS Julián, Memorias de la lucha campesina: Cristiano, mestizo y tomador de fundo, Santiago de Chile, Lom, 2009.

${ }^{44}$ BAEZA, op. cit.
} 
al momento histórico y en relación a su política partidaria, designó militantes para el desarrollo de trabajo en ciertas áreas rurales del país.

"Yo, hijo de campesino, soy nacido y criado en el campo, y por lo tanto, cuando se me empiezan a asignar tareas, desde el punto de vista de mi experiencia, lo que más me relaciona, tiene que ver con el trabajo campesino, entonces asumo la responsabilidad de empezar a trabajar en la provincia de Malleco en el tema campesino" 45 .

La designación de dichos militantes, se debe al contexto afín que poseía cada militante en el periodo, de esta forma el MIR durante la época tenía como política que sus cuadros salieran y tuvieran contacto con la realidad social en los espacios que se hallaban inmersos, realidad donde debían ejercer la política del partido.

La primera vez que recorrimos la zona de Neltume y la comunidad de Trafún Chico con el Vicente y el Pepe, fueron alrededor de 25 días; de vuelta a Valdivia con el Pepe planteamos la situación, nuestra experiencia a nuestro Comité Regional del MIR; y el verano que viene, verano del 69 el mismo proceso, ya se hablaba de la Unidad Popular, y nosotros, el partido ya estábamos, ya pensando seriamente en irnos a la montaña, y con la gente que nosotros conocimos el año anterior, entramos más directamente ${ }^{46}$.

El destinar que los militantes tuvieran contacto con la realidad social del país, en el caso específico investigado, es decir en el contexto campesino, hace que antes de la conformación del frente intermedio de masas como tal, militantes del MIR ya se hubieran aproximado a las áreas rurales para generar los contactos necesarios para el fin que buscaba el partido.

Yo me fui a vivir y trabajar como médico recién recibido en agosto de 1969 a la localidad de Futrono. Rápidamente entré en contacto con las comunidades mapuches, las organizaciones campesinas y los sindicatos madereros" ${ }^{\prime 7}$.

Como podemos notar, ya a finales de la década de 1960 el MIR inicia su trabajo en ciertos sectores rurales del país, sectores donde existía población campesina pobre, tanto mapuche como chilena, acosada por la explotación latifundista predominante en la época. ${ }^{48}$

\footnotetext{
${ }^{45}$ Entrevistado MIR 1.

${ }^{46}$ Entrevistado MIR 2

${ }^{47}$ Entrevistado MIR 3

48 "Las tierras mapuche bajo títulos de dominio del Estado continuaron soportando las arremetidas de colonos wingkas-(chilenos), que las redujeron casi a la mitad en un par de décadas, con la práctica de compras fraudulentas, corridas de cerco y matonaje-amenazas-terrorismo practicado por terratenientes chilenos, ante la vista gorda de la justicia chilena."(Marimán J. 2002, p.49). Proceso que venía profundizándose desde la colonización de la Araucanía, hasta nuestros días.
} 
Las primeras experiencias que se desarrollaran, por ahí, en la zona de Lautaro, con el Paine, fue en el año 68, que es el año que corresponde a la definición que hace la dirección del MIR, recientemente fundado, de enviar a sus militantes desde las universidades, al campo, a la población, te fijas, a hacer la política ahí ${ }^{49}$.

Podemos decir que se configuraba dentro del MIR cierto programa, que tenía como fin acercar a sus militantes a la realidad social que se percibía durante el periodo. Este mismo acercamiento designado de la dirección nacional ${ }^{50}$ hacia las personas que pertenecían al movimiento hizo que estos últimos al adentrarse al área rural, además de encontrarse con campesinos chilenos, se vieran inmersos en una serie de reducciones mapuche que existían en la época, las cuales en ciertos casos convivían con los caseríos de los chilenos. Estas reducciones se ubicaban principalmente en la Región de La Araucanía y del Bio Bío. Las acciones que se efectuaron en estos territorios, fueron la base para la conformación de lo que luego pasaría a llamarse Movimiento Campesino Revolucionario.

Ya existiendo una base de adherencia en las diversas comunidades, junto con acciones directas puestas en marcha, como lo fueron las corridas de cerco, directamente relacionadas con la problemática de tierra que poseía el pueblo mapuche, se formaliza el movimiento. Entendiendo que el MCR se funda como tal en 1970, y que dentro de su orgánica confluían diferentes sectores campesinos, entre ellos mapuche y chilenos, podemos dar cuenta que dentro del accionar que poseyó este frente intermedio de masas del MIR, se pueden vislumbrar elementos identitarios mapuche, los cuales percibimos en las acciones directas que se llevaron a cabo.

La nula diferenciación efectuada por el MIR en la época, ha sido fruto de críticas por parte de estudiosos y académicos chilenos. Pero pese a que en la formalidad no se generaba una especificidad del trabajo con sectores Mapuche, en relación a los militantes que decidieron hacer trabajo político en comunidades, así como aquellos que fueron designados, planteamos que estos poseían una clara conciencia en relación a las personas con las que se encontraban trabajando. Y podemos postular que sí se generaba una diferenciación en relación a la cultura para efectos del accionar, pero no en la política oficial del partido.

Nosotros respetábamos la organización propia del lugar, si bien es cierto, podíamos llevar un contacto de una persona, pero si existía la organización, el contacto, lo hacíamos con la organización porque necesitábamos incorporar al conjunto de esa comunidad en la lucha que queríamos dar (...) el concepto también de nosotros de

\footnotetext{
${ }^{49}$ Entrevistado MIR 1

${ }^{50}$ En el periodo el comité central del MIR estaba integrado por: Miguel Enríquez, Bautista van Shouwen, Luciano Cruz, Edgardo Enríquez E., Sergio Zorrilla, Sergio Pérez, Jorge Grez, Ricardo Ruz, Patricio Figueroa, Carlos, Jara. Nahuel Figueroa, Norman Gamboa, Luis Vítale, Washington Figueroa y el cro. Genaro. El Secretariado lo confirmaron: Miguel, Luciano, Bautista, Zorrilla y Pérez (NARANJO, Pedro. AHUMADA, Mauricio. GARCÉS, Mario. PINTO, Julio. Miguel Enríquez y el proyecto revolucionario en Chile. Discursos y documentos del Movimiento de Izquierda Revolucionaria, MIR, Santiago de Chile, Lom, 2004).
} 
participar, tenía que ver con que la gente lo hiciera, nosotros éramos un elemento de ayudar, a orientar, pero queríamos que la gente participara, se diera cuenta y aprendiera más como debía ser y además incorporar el elemento de acción militar, no era una, no era como decirte, no era una pelotera de gente que sale corriendo desesperada a tomarse algo que estaba como abandonado, no; la idea era hacer todo un proceso de formación en que le permitiera a ellos a darse cuenta de que hay que incorporar en la lucha los elementos militares ${ }^{51}$.

La discusión de cómo los militantes del MIR que se encontraban trabajando en zonas donde existían reducciones Mapuche llegaban a tomar una conciencia del área en la cual pretendían y hacían trabajo político, es fundamental para vislumbrar el porqué de la adhesión de mapuche al frente intermedio de masas. Uno de los aspectos que conllevaba una adherencia es lo que se logra vislumbrar en la cita anterior, en donde se da cuenta de cómo era el mecanismo cuando se llegaba a un sector en donde se pretendía efectuar algún tipo de acción o trabajo. Esto es el respetar la organización del lugar y seguir los pasos claves para poder adentrarse, respetando sus dinámicas culturales, lo que se denomina como "rapport", proceso clave para una buena acogida y de esta manera difundir las ideas que traían los chilenos en relación a las acciones que debían realizarse para recuperar territorio.

Cabe destacar que el mecanismo de llegada a las comunidades variaba con el contexto, lo cual de por sí hace variable el accionar del mismo MCR en relación a donde se encontraba. La no existencia de un manual, o de instrucciones formales de parte del MIR hacia sus militantes, hace imposible generar una clasificación universal del modus operandi que poseían los diversos militantes y adherentes al movimiento. Respecto a esto, adherentes mapuche de la comunidad de Collico, en la comuna de Puerto Saavedra en la Región de La Araucanía, relatan que el accionar que poseyó el MCR en la zona contrasta con la última cita mencionada.

No sé cómo lo hacían estos jóvenes revolucionarios para organizar a la gente, pero como les dije yo, a mí me pillaron medio curaito, los encuentro arriba y andaban, no sé cuántos andaban, entonces me dicen vamos, vamos les dije, y así mismo como andaba fui nomás. Después nos desalojaron al otro día ${ }^{52}$.

Esto nos hace dar cuenta de la heterogeneidad de discursos que se configuraron, y la existencia de varias formas de accionar por parte del MCR en las comunidades mapuche donde se veía involucrado. Dentro de las formas de acción, encontramos la visualizada en la cita anterior, donde existía una manera inmediata y bastante informal a la hora de agrupar a la gente para la recuperación del fundo. No obstante, no obviamos la existencia de estudios de terreno y de las condiciones apropiadas para la acción directa por parte de quienes la incitaban, como también la existencia de otros contextos, lo cual fue clave a la hora de las tomas de fundo, considerando la gran cantidad de hectáreas recuperadas por el MCR entre 1970 y 1973. Respecto a lo anterior es importante también señalar la urgencia

\footnotetext{
${ }^{51}$ Entrevistado MIR 1

${ }^{52}$ Entrevistado Mapuche 1
} 
por parte de las propias comunidades mapuche por recuperar los terrenos usurpados y que durante ese periodo se encontraban en manos de latifundistas, quienes las explotaban.

\section{Nociones de Identidad y pertenencia de los Mapuche, dentro de las acciones directas propiciadas por el Movimiento Campesino Revolucionario}

Antes de profundizar en el análisis de estas nociones dentro del MCR, es pertinente dar cuenta de que el MIR bajo la clasificación propuesta por Alain Touraine ${ }^{53}$ correspondería a la definición de movimiento social, ya que existe una población comprometida en nombre de quien se provocan las acciones, además de generar conflicto teniendo como enemigo un ente abstracto como lo es el capitalismo de Estado. Llevando lo anterior al contexto de esta investigación, la lucha que llevaba a cabo el MIR es una que ataca un conflicto general que aglutinaría a un número importante de la población, que es la explotación hacia las clases oprimidas por la clase explotadora que ostenta el poder económico. También tomando en consideración las definiciones de Touraine ${ }^{54}$, el MIR cabe dentro de la clasificación de movimiento con acciones revolucionarias, esto porque no se buscaba sólo un asalto al poder, sino que involucraba una destrucción del sistema de clases, con el fin último que es el socialismo. En nuestro análisis de la identidad étnica mapuche nos hace sentido comprenderla como lo afirma Andrea Aravena ${ }^{55}$, dentro de tres ejes catalogando el análisis en un nivel microsocial, mesosocial y macrosocial. Dentro del nivel microsocial que involucra la conciencia individual que poseen las personas en torno a la pertenencia a un grupo en particular, podemos citar el testimonio de Lucy Traipe, quien señala:

Pero en la época del MCR y del MIR nosotros no hablábamos como pueblo mapuche, hablábamos del campesinado en general, se generalizaba. Lo que nos hacía diferentes a los mapuche de los no mapuche radica en cómo vivir de la tierra y cómo pensar. El mapuche no hace una puerta porque se le ocurrió ahí, la hace ahí para mirar el sol directamente cuando se levanta ${ }^{56}$.

Podemos notar que existía dentro de las personas mapuche involucradas con el MCR una conciencia de pertenencia a un grupo social particular, en este caso a un grupo étnico, el pueblo mapuche. Otro de los testimonios que nos pueden atestiguar que los mapuche dentro del MCR poseían conciencia de pertenencia a un grupo social, es lo que expresa Rafael Railaf:

Y el MIR llega y se plantea, viene instruyendo de cómo ser mirista. Y nosotros decimos 'No. Tenemos que también identificarnos con nuestro

\footnotetext{
${ }^{53}$ ZAPATA A, Ciudadanía, clase y etnicidad. Un estudio sociológico sobre la acción colectiva en Bolivia a comienzos del siglo XXI, Bolivia, Ediciones Yachawasi, 2006.

${ }^{54}$ Ibid.

${ }^{55}$ ARAVENA, op. cit.

${ }^{56}$ Lucy Traipe, citado en RAILAF, op. cit., p. 47.
} 
pueblo, para estar siempre junto a ellos y si nos convertimos demasiado en partido, nuestro pueblo nos va a aborrecer ${ }^{57}$.

La anterior cita da cuenta de la auto adscripción a la cultura mapuche que poseían las personas, esto considerando la política del MIR de aquellos años, la cual se sustentaba en el discurso del campesinado, discurso que era relegado una vez llegando a las comunidades mapuche, al dar cuenta de las diferencias identitarias que enunciaban los actores sociales.

Esto nos hace notar la diferencia que existió entre lo que sale en el papel y lo que conllevaron las acciones in-situ, donde la etnicidad sale a la palestra y se demuestra generando las fronteras étnicas como las que postula Fredrik Barth ${ }^{58}$, limites tangibles en la diferencia que pronuncia Lucy Traipe, las que tienen que ver con el cuidado, así como con las diferencias culturales que ella pronuncia.

Respecto al nivel mesosocial, Aravena ${ }^{59}$ postula que " a nivel grupal, la etnicidad corresponde principalmente a la movilización étnica y a la acción colectiva de carácter étnico". En este sentido, comprendiendo que las acciones impulsadas por el MCR englobaban tanto tomas de fundos como corridas de cerco, es en estas acciones donde podemos encontrar elementos correspondientes a la identidad étnica dentro del accionar del MCR, tomando en consideración lo propuesto por Marimán ${ }^{60}$, quien postula que el etnicismo es una herramienta para grupos que se plantean diferentes estrategias, conteniendo dentro de estos grupos a aquellos que han vivido situaciones de conflicto. Tomando en consideración lo relacionado con el conflicto, en donde la usurpación de tierras mapuche por parte de latifundistas chilenos y colonos es algo tangible, pasa a ser un elemento étnico que concierne sólo al pueblo mapuche, por tanto, alcanza ribetes identitarios ya que marca la diferencia con los demás chilenos que participaban del movimiento.

Claro, uno, niño, no piensa mucho. Entonces una persona tenía más terreno que toda la comunidad junta, que además antes era de nosotros. $Y$ te enojas más todavía cuando te das cuenta que eso era tuyo, de tu papá, de la familia. Esas son las cosas que te llevan a participar en las-acciones directas- que las organizaba el MIR ${ }^{61}$.

Se puede notar que este etnicismo es un aspecto propio del pueblo mapuche, el que tiene que ver con la problemática de la tierra, lo que se une con la cita mencionada previamente en donde aquel motivo es el que empuja a la gente perteneciente a este pueblo a participar dentro del accionar por la recuperación de tierras. Diferencia que se puede ver

\footnotetext{
${ }^{57}$ Rafael Railaf citado en RAILAF, op. cit., p. 56.

${ }^{58}$ BARTH, op. cit.

${ }^{59}$ ARAVENA, op. cit.

${ }^{60}$ MARIMAN, op. cit.

${ }^{61}$ Rudecindo Quinchavil citado en RAILAF, op. cit., p. 29.
} 
acentuada en la siguiente cita: "La corrida de cerco era por las tierras usurpadas y era sólo mapuche. La toma de fundo y el asentamiento incluía también a los winkas" "62.

Respecto a lo que concierne a la toma y recuperación de terreno, podemos decir que claramente se puede distinguir el nivel meso social o grupal de la etnicidad, en donde existen y se acentúan las diferencias en las mismas acciones directas, diferencias entre wingka y mapuche, por un pasado en particular; una historia en conjunto como pueblo y una cultura que los unifica como pueblo mapuche.

En el último nivel que propone Aravena ${ }^{63}$, el nivel estructural o macro social, la etnicidad se ve determinada por otros factores, tales como el político, económico y social. De esta manera lo anterior bajo nuestro punto de vista se ve reflejado en lo propuesto por José Marimán ${ }^{64}$ quien señala:

En el curso de los enfrentamientos de los mapuches con hombres de negocios chilenos - incluidos en esta categoría los terratenientes en la región mapuche- y el estado, las alusiones en las proclamas mapuche a la idea de que tuvieron un territorio y que este les fue expoliado por el estado chileno, reflejan una memoria histórica que es parte de su etnicidad y de su identidad $^{65}$.

Se configura así un contexto político en el cual no existe ninguna actitud por parte del Estado chileno respecto a las demandas mapuche por las tierras que les fueron usurpadas. Esto se suma a la explotación que genera el latifundio-estado, el cual tiende a configurar una economía miserable. En lo que respecta al aspecto social, se forja una imagen desfigurada de lo que es el mapuche, imagen enarbolada por los explotadores, generando así un contexto donde la etnicidad se manifiesta y es moldeada a la vez que se forja una identidad a la cual adscribe un grupo social.

Estos aspectos nos permiten visualizar la etnicidad propia de las personas, etnicidad que se ve moldeada desde que el Estado chileno margina al pueblo mapuche en reducciones, generando así un pueblo sin tierras (las cuales fueron robadas), creando las condiciones propicias para que estas personas, mujeres, hombres y niños entren a formar parte del inquilinaje chileno, pasando a ser parte de los explotados del campo sin acceso a tierras propias para restaurar su economía a base de la agricultura, sino que muy por el contrario, se convertían en una pieza más del modelo mercantil imperante.

Nosotros antes éramos pobres, pobres, yo a mis hijos les digo que cuando recién nos juntamos con mi marido, no teníamos una cuchara, ¿Dónde formamos hogar? Hicimos casa, era pura paja, clavo con paja, techo con paja (...) porque éramos pobres ${ }^{66}$

\footnotetext{
${ }^{62}$ Rafael Railaf citado en RAILAF, op. cit., 58.

${ }^{63}$ ARAVENA, op. cit.

${ }^{64}$ MARIMÁN, op. cit.

${ }^{65}$ MARIMÁN, op. cit., p. 37.

${ }^{66}$ Entrevistado Mapuche 2
} 
En torno a lo anterior, tampoco es difícil darse cuenta del porqué el MIR forjó el MCR como una orgánica integradora de la totalidad de los pobres del campo, considerándolos a todos como campesinos. Esto debido a que chilenos y mapuche vivían en las mismas o muy similares condiciones de miseria, compartiendo condiciones de explotación. Alejandro Saavedra ${ }^{67}$ y luego José Marimán ${ }^{68}$, contemplan lo concerniente a la pluri-identidad, bajo este concepto se identifica una identidad de clase, la cual pasaría a ser campesina considerando la explotación que sufría esta clase social, y una identidad étnica, tomando en consideración los aspectos culturales mapuche diferenciadores de los chilenos.

La política que poseía el MCR, podríamos decir que fue tomada por parte de los mapuche como una herramienta con la cual se podían solucionar los temas concernientes a su clase social, a la pobreza que vivían a diario, y también para hacer válidas sus reivindicaciones étnicas, las cuales se concretaron a través de las corridas de cerco en el sur de Chile. De esta manera clasificando al MCR en torno a lo propuesto por Alain Touraine $^{69}$, podemos decir que este movimiento se encasilla dentro de la clasificación de acciones revolucionarias, ya que involucra una destrucción de las relaciones de clase, a través de una acción revolucionaria en donde se desafía a la dominación de clase en nombre de la reapropiación de todas las formas de autoproducción de la sociedad por parte de la comunidad. Así podemos notar los principios analíticos de identidad -¿en nombre de quién se lucha?- , un principio de oposición - ¿cuál es el adversario?- y un principio de totalidad ¿qué posición se toma frente a las orientaciones del desarrollo $?^{70}-$, en las siguientes tablas ${ }^{71}$ en donde se hace la diferencia con el Movimiento de Izquierda Revolucionaria.

Tabla I: Movimiento de Izquierda Revolucionaria con relación al principio de identidad, oposición y totalidad.

\begin{tabular}{|c|c|}
\hline Principios & Movimiento de Izquierda Revolucionaria \\
\hline Principio de Identidad & Pobres del campo y la ciudad \\
\hline Principio de Oposición & $\begin{array}{c}\text { Contra quienes ostentan el poder } \\
\text { socioeconómico de la sociedad (Capitalismo) }\end{array}$ \\
\hline Principio de Totalidad & Para llegar a una patria socialista \\
\hline
\end{tabular}

Tabla II: Movimiento Campesino Revolucionario con relación al principio de identidad, oposición y totalidad

\begin{tabular}{|c|c|}
\hline Principios & Movimiento Campesino Revolucionario \\
\hline Principio de Identidad & Explotados del campo \\
\hline
\end{tabular}

\footnotetext{
${ }^{67}$ SAAVEDRA, op. cit.

${ }^{68}$ MARIMÁN, op. cit.

${ }^{69}$ ZAPATA, op. cit., pp. 47-50.

${ }^{70}$ Ibid., p. 40.

${ }^{71}$ Ejemplo extraído de FELDIS, op. cit., p. 5, modificado por los autores.
} 


\begin{tabular}{|c|c|}
\hline Principio de Oposición & Contra el latifundista \\
\hline Principio de Totalidad & $\begin{array}{c}\text { Para terminar con la propiedad terrateniente y la } \\
\text { burguesía agraria }\end{array}$ \\
\hline
\end{tabular}

Como podemos notar en los cuadros sintéticos, el MIR aglutina una mayor cantidad de sectores sociales, tomando en consideración los explotados de todos los sectores para así alcanzar su objetivo; a diferencia del MCR, que al ser un frente intermedio de masas se enfoca en una lucha más específica, la perteneciente al campo de nuestro país. Es dentro de este movimiento donde el principio de identidad, el cual genera unidad dentro de las personas que participan del MCR es de suma importancia, y sirve para entender de mejor manera la participación mapuche. De esta forma el principio de identidad corresponde a la identidad de clase, en este caso campesino. Es así como damos cuenta que la unidad entre chilenos y mapuche se forja por una identidad en común que arrastraban desde que el mapuche se volvió campesino y se le obligó a ser inquilino. Aspecto que los une con los chilenos que vivían la misma realidad social y económica.

Comprendiendo lo anterior, damos cuenta de que el MCR a través de sus acciones directas efectivamente tomó aspectos identitarios y étnicos del pueblo mapuche para incluirlos en la lucha, por lo cual podemos postular que simultáneamente existía un submovimiento guiado por principios más específicos, esto descrito en el siguiente cuadro:

Tabla III: Mapuche dentro del Movimiento Campesino Revolucionario con relación al principio de identidad, oposición y totalidad.

\begin{tabular}{|c|c|}
\hline Principios & $\begin{array}{c}\text { Mapuche dentro del Movimiento Campesino } \\
\text { Revolucionario }\end{array}$ \\
\hline Principio de Identidad & Identidad étnica Mapuche \\
\hline Principio de Oposición & Contra latifundista que quitó tierras ancestrales \\
\hline Principio de Totalidad & $\begin{array}{c}\text { La recuperación de territorio ancestral para } \\
\text { devolverlo a la comunidad mapuche }\end{array}$ \\
\hline
\end{tabular}

Es de esta manera como el mapuche al estar dentro del MCR confluía en dos identidades; una de clase que es la de campesino, y una étnica que es la pertenencia al pueblo mapuche. La etnicidad e identidad dentro del MCR para los mapuche se configuraba contra un opositor, o mejor llamado enemigo histórico, que corresponde al latifundista quien robó las tierras. También la etnicidad mapuche se construye dentro del mismo movimiento donde, como notamos, se configura una frontera con el chileno, con el mismo campesino junto a quien se lucha, como también una diferencia con el afuerino que venía a incentivar la realización de acciones directas. También podemos decir que desde el MCR existe una política identitaria que acentúa las diferencias étnicas entre quienes participaban en sus acciones, política que se puede distinguir claramente al analizar el tipo de actor 
social que participaba en determinadas acciones: las corridas de cerco involucraban sólo a mapuche, mientras que las tomas de fundo involucraban tanto al campesinado chileno y mapuche.

Así dentro de las mismas acciones directas, los mapuche que participaban dentro de este movimiento forjaron fronteras étnicas con sus pares, tanto como con su enemigo. Pero también se vislumbra las múltiples identidades que poseían los mapuche, la cual se configura por las décadas de explotación que condujeron a que los mapuche adquirieran una identidad de clase. De esta forma, con relación a los mapuche dentro del MCR podemos decir que se configuraban y se amalgamaban ambas identidades, las cuales desembocaban en dos objetivos: por una parte la recuperación de tierras ancestrales (etnicidad), y por otra, la recuperación de territorio para la explotación colectiva (clase).

\section{Conclusiones}

A través de los resultados que brinda la presente investigación podemos concluir que las acciones propiciadas por el MCR en los campos del sur de Chile y en las diversas comunidades mapuche, era una de las tantas acciones dirigidas a la generación de las condiciones propicias en el caso que llegase a concretarse una guerrilla en el país. De esta manera la existencia de una gran población que apoyara al MIR serviría para generar cercos de ayudistas, así como para evitar y contener la posible represión que se podía esperar al enfrentar política y militarmente al enemigo.

La política del MIR tendía directamente a activar estos elementos, como lo podemos vislumbrar en diversas publicaciones y escritos, pero de la misma forma no podemos dejar de lado los discursos que dan cuenta de la realidad vivida en ese periodo en diferentes zonas del país, donde los militantes daban cuenta de una diferencia entre los mapuche y chilenos con los que deseaban empezar un trabajo político.

Tomando en consideración los objetivos de la investigación podemos decir que la relación entre el MIR y el pueblo mapuche empezó mucho antes de la conformación del frente intermedio de masas llamado Movimiento Campesino Revolucionario, esto considerando que el MIR hacia finales de la década de 1960 planteó como política de partido ligar a sus militantes con las diversas realidades sociales que existían en Chile, lo que luego de aproximadamente tres años de trabajo dio como fruto la conformación de un frente aglutinador de masas como lo fue el MCR, que tiene su nacimiento en 1970.

Considerando la política del MCR y su relación con el pueblo mapuche, damos cuenta que no existía en su línea programática una visión específica hacia este conglomerado social, aglutinando de esta forma tanto a campesinos chilenos como mapuche dentro del movimiento. Esto deja ver, por tanto, que existió un trabajo con diferentes comunidades mapuche, pero sin ahondar en el tema étnico. A pesar de ello, sí se puede rescatar a través de la oralidad, que los militantes del MIR que hicieron trabajo político en comunidades mapuche lograron cierta perspectiva hacia lo étnico, entendiéndose como el MCR logró que los mapuche participaran con tanta motivación, haciendo el trabajo conjunto. Uno de los aspectos que bajo nuestra perspectiva es de suma importancia en lo concerniente al accionar del MCR y la inclusión de los mapuche en este 
tipo de lucha, es que los militantes chilenos del MIR vislumbraron una problemática arraigada en la cultura de estas personas, el conflicto de tierras que poseían desde tiempos de la colonia. De esta forma podemos manifestar que el MCR sí encontró y potenció un tema étnico, el cual fue aprovechado tanto por mapuche para recuperar sus tierras, como por los mismos militantes chilenos para agilizar el proceso revolucionario.

Dentro de las mismas acciones directas, como la toma de fundo y las corridas de cerco, es donde podemos decir que se puede identificar con mayor claridad un componente étnico en la lucha propiciada por el MCR, ya que era aquí donde se vislumbraban las diferencias identitarias entre mapuche y chilenos. A través del análisis realizado podemos señalar que los militantes chilenos del MCR y del MIR pusieron especial atención a estas diferencias, ya que en las tomas de fundo participaban tanto chilenos como mapuche, y en las corridas de cerco sólo mapuche, generándose una diferencia dentro del propio movimiento tomando parámetros culturales para las acciones a realizar. A su vez dentro de esta lucha se deja ver la configuración de identidades múltiples, puesto que debido a la campesinización forzada del mapuche, éste consideraba su lucha parte de la lucha que llevaban todos los pobres del campo en esos años.

Los mapuche en la condición social en la cual se encontraban durante la década de 1960, vislumbraron en el MCR una herramienta para recuperar su territorio ancestral que fue quitado de sus manos, y el MCR viendo en los mapuche una fuerza social revolucionaria, hizo que los objetivos se entrecruzaran y forjaran una historia en común. De acuerdo a esto podemos decir que en las acciones directas propiciadas por el Movimiento Campesino Revolucionario se dejaron ver elementos identitarios y étnicos del pueblo mapuche, elementos que no podían dejar de existir ya que son una cultura diferente a la chilena. No podían dejarse de lado porque siempre van a estar presentes en las personas que son parte y se definen como mapuche.

Considerando aquella miseria y pobreza, damos cuenta que ésta se arrastra desde que al mapuche se le obligó a hacerse campesino, se le obligó a que se hiciera inquilino y se apatronara para ganar un plato de comida al día y así poder sobrevivir, pero teniendo en claro sus raíces, su herencia y que aquella tierra que estaba trabajando para otros, realmente le pertenecía a él, a ella y a toda su comunidad. De esta forma, sus dos identidades amalgamadas, una identidad de clase correspondiente a la explotación que sufría a diario pasando a formar parte del campesinado chileno de ese entonces, y una conciencia étnica considerando su cultura, su modo de vida, su pensamiento, confluyeron en una orgánica marxista-leninista como lo fue el Movimiento Campesino Revolucionario.

Para finalizar, considerando la aproximación teórica que esta investigación propone para tratar de vislumbrar cómo se configuraron las relaciones entre un grupo revolucionario y el pueblo Mapuche, los investigadores se encuentran consientes que esto corresponde a una aproximación, que si bien puede ser usada y replicada para el estudio de relaciones entre pueblos originarios y grupos políticos, en otros casos no sería de utilidad debido a los diferentes contextos que durante ciertos periodos históricos pueden generarse. Es así como la investigación, aparte de proponer, también busca incentivar el estudio que involucre a otros movimientos como lo puede ser el Partido Comunista Revolucionario, el que tuvo un accionar directo con el pueblo Mapuche en el sur de Chile. 


\section{Bibliografía}

ALFARO, María. La construcción del Movimiento Campesino a partir de las tomas de fundos entre 1971 y 1972. Informe Final de Seminario de Grado Licenciado en Historia. Santiago de Chile, Universidad de Chile, Facultad de Filosofía y Humanidades. Departamento de Ciencias Históricas, 2011.

ARAVENA, Andrea. "El rol de la memoria colectiva y de la memoria individual en la conversión identitaria mapuche". En Estudios Atacameños. 2003, vol. 26, p. 89-96.

BAEZA, Manuel. De las metodología cualitativas en investigación científico-social. Diseño y uso de instrumentos en la producción de sentido. Concepción, Chile, Universidad de Concepción, 2002.

BARTH, Fredrik. Los grupos étnicos y sus fronteras, México, Fondo de Cultura Económica, 1976.

BARTOLOMÉ, Miguel. Procesos interculturales. Antropología política del pluralismo cultural en América Latina. México, Siglo XXI Editores, 2006.

BASTÍAS, Julián. Memorias de la lucha campesina: Cristiano, mestizo y tomador de fundo, Santiago de Chile, LOM, 2009.

BENGOA, José. Historia de un Conflicto: El Estado y los Mapuches en el Siglo XX, Santiago de Chile, Editorial Planeta Chilena S.A., 1999.

BENGOA, José. (compilador). La Memoria Olvidada. Historia de los Pueblos Indígenas de Chile, Santiago de Chile, Cuadernos Bicentenario, 2004.

CHIHUAILAF, Arauco. "Los mapuches y el gobierno de Salvador Allende (1970-1973)". En: Sociedad y discurso, AAU. 2004, vol.5, p. 1-11.

CHONCHOL, Jacques. El desarrollo de América Latina y la Reforma Agraria, Santiago de Chile, Editorial del Pacifico, 1964.

CORREA, Martín. MOLINA, Raúl. YÁÑEZ, Nancy. La reforma agraria y las tierras mapuches, Chile 1962 - 1975, Santiago de Chile, Lom, 2005.

DÍAZ, Joel. QUEZADA, Edgardo. Estado, Reforma Agraria y Campesinos. El conflicto por la tierra en el Chile central desde mediados de siglo. Tesis de grado,, Universidad de Concepción, 2000.

FELDIS, J. Alain Touraine, La sociología, ciencia de los movimientos sociales. En: Revista Criterio jurídico, político y social, Universidad Autónoma Gabriel René Moreno, 2003.

FOERSTER, Rolf. MONTECINOS, Sonia. Organizaciones, líderes y contiendas mapuche (1900-1970), Santiago de Chile, Ediciones CEM, 1988.

MALLON, Florencia. La sangre del copihue: la comunidad mapuche de Nicolás Ailío y el estado chileno 1906-2001, Santiago de Chile, Lom, 2004.

MARIMÁN, José. Autodeterminación, Ideas políticas mapuche en el albor del siglo XXI, Santiago de Chile, Lom, 2012.

MELLA, Eduardo, Los mapuche ante la justicia. La criminalización de la protesta indígena en Chile, Santiago de Chile, LOM - Observatorio de los Pueblos Indígenas, 2007.

NARANJO, Pedro. AHUMADA, Mauricio. GARCÉS, Mario. PINTO, Julio. Miguel Enríquez y el proyecto revolucionario en Chile. Discursos y documentos del Movimiento de Izquierda Revolucionaria, MIR, Santiago de Chile, Lom, 2004.

RAILAF, Rafael. A desalambrar: historias de Mapuches y Chilenos en la lucha por la tierra, Chile, Editorial Ayun, 2006.

SAAVEDRA, Alejandro. Los mapuche en la sociedad chilena actual, Santiago de Chile, Lom, 2002.

SAMANIEGO, Augusto. RUIZ, Carlos. Mentalidades y políticas wingka: Pueblo Mapuche, entre golpe y golpe (de Ibáñez a Pinochet), vol. 7, Editorial CSIC-CSIC Press, 2007.

SANDOVAL, Carlos. Investigación Cualitativa, Bogotá, ARFO editores, 2002.

TOLEDO, Víctor, El pueblo mapuche, derechos colectivos y territorio: Desafíos para la sustentabilidad democrática, Santiago de Chile, Lom, 2006.

ZAPATA, A. Ciudadanía, Clase y Etnicidad. Un estudio sociológico sobre la acción colectiva en Bolivia a comienzos del siglo XXI, Bolivia, Ediciones Yachaywasi, 2006. 